\title{
O GOSTO PELO MUNDO: A GLOBALIZAÇÃO DA CULTURA APREENDIDA PELO COSMOPOLITISMO ESTÉTICO-CULTURAL DOS JOVENS NA FRANÇA'
}

\section{TASTE AROUND THE WORLD: CULTURE GLOBALIZATION SEIZED BY AESTHETICAL-CULTURAL COSMOPOLITANISM OF YOUNGSTERS IN FRANCE}

\author{
Vincenzo Cicchelli* \\ Sylvie Octobre**
}

\section{Introdução}

Disponíveis em (quase) todos os pontos do globo, certos produtos culturais de grande consumo contribuem para a construção de uma representação de um mundo, ao mesmo tempo, plural - em virtude da diversidade dos produtos que circulam internacionalmente - e unificado por certas referências culturais. Isto tem contribuído para fomentar a idéia segundo a qual a diversidade cultural - o mundo como um mosaico de produtos culturais - fornece aos indivíduos recursos (referências iconográficas e narrativas, imaginários) que lhes dão o sentimento de habitar um mundo comum (CICCHELLI, 2016). Os jovens são atores importantes neste processo de globalização da cultura, porque estão implicados nos consumos culturais, mas igualmente porque são oriundos de composições geracionais multiculturais, sensíveis às injunções dispostas pelas mobilidades (turística, estudantil, profissional...). (DONNAT e LEVY, 2007; DONNAT 2009, OCTOBRE, 2014).

Frente a isso, como não indagar-se a propósito do papel do consumo e dos ima-

\footnotetext{
* Doutor em Sociologia. Professor na Université Paris Descartes (Paris/FR) e pesquisador vinculado ao Groupe d'Etude des Méthodes de l'Analyse Sociologique de la Sorbonne - GEMASS (Paris IV-CNRS). vicenzo.cicchelli@msh-paris.fr.

** Doutora em Sociologia. Pesquisadora no Département des Etudes, de la Prospective et des Statistiques (DEPS) do Ministério da Cultura e da Comunicação, e pesquisadora associada ao GEMASS (Paris IV-CNRS). sylvie.octobre@culture.gouv.fr.

1. 0 presente texto consiste numa versão retrabalhada de "Les cultures juvéniles à l'ère de la globalisation: une approche par le cosmopolitisme esthético-culturel”. (CICCHELLI e OCTOBRE, 2017). Os tratamentos estatísticos são de Nathalie Berthomier, estatística do DEPS. Tradução do artigo de Vassili Rivron. Revisão técnica de Mariana Mont'Alverne Barreto Lima.
} 
ginários culturais na emergência de uma relação cosmopolita com o mundo? Os jovens estão expostos à difusão mundial de produtos culturais anglo-saxões - de Harry Potter a Hunger Games, passando por Games of Thrones - mas também a fluxos culturais asiáticos - do Gangnam Style ao mangá ou aos anime japoneses - sem ignorarem, ainda, o samba brasileiro ou o cinema indiano de Bollywood. Esses fluxos dos produtos internacionais exprimem os equilíbrios geopolíticos, assim como um soft power, cuja dimensão cultural é preponderante (IWABUCHI, 2002).

0 conceito de cosmopolitismo estéticocultural é aqui mobilizado para analisar, além dos fenômenos de internacionalização dos repertórios de consumo, as mutações provenientes dos consumos culturais, cujo impacto se faz sentir sobre a apreensão da alteridade (CICCHELLI, OCTOBRE e RIEGEL, 2016). Para aproximar-nos deste cosmopolitismo, os consumos cotidianos, preponderantes nos universos culturais juvenis, foram privilegiados por ilustrarem formas de cosmopolitismo muito mais interessantes ainda que muitas vezes, banalizadas, quando não invisiveis (KUIPERS e DE KLOET, 2009). Formas mais raras - ir ao teatro, ao museu, ou tocar um instrumento musical - foram excluídas. Apreenderemos, então, aqui, o cosmopolitismo estético-cultural por meio do consumo de séries televisivas, filmes, programas de televisão, música gravada, livros, jornais ou revistas, histórias em quadrinhos, consultas a websites e blogs, usos das redes sociais, práticas dos jogos de videogames, etc. (CICCHELLI e OCTOBRE, 2017).

\section{Elementos metodológicos: um duplo protocolo baseado em consumos e imaginários}

São raras as pesquisas, em particular quantitativas, que estudam a apropriação, por uma população, de obras e produtos culturais estrangeiros. Para tratar deste assunto, um protocolo original, porque especificamente dedicado à questão do cosmopolitismo, foi implementado associando:

1- por um lado, uma pesquisa face a face, por meio de questionário, realizada na França em 2015, com uma amostra representativa de pouco mais de 1600 jovens, com idades entre 18 e 29 anos, para apreender a maneira como se apropriam das obras e dos produtos culturais de ampla circulação internacional. Aqui, o cosmopolitismo é pensado a partir de dois tipos de abertura: uma relativa às produções estrangeiras, aos modos específicos de consumo e a outra à construção dos imaginários globais.

0 questionário composto por 157 questões tratava dos cinco temas principais:

a) os consumos midiáticos: filmes, séries, programas de TV, música gravada, emissões de rádio, videogames, leitura de quadrinhos, revistas e livros, consultas a websites e blogs e o uso das redes sociais. Para cada item, considerou-se, a proporção entre consumos nacionais e estrangeiros, as preferências, os modos privilegiados de consumo (língua de origem ou não), assim como, de maneira mais clássica, a intensidade dos consumos e gostos por certos gêneros em particular;

b) os imaginários estéticos e culturais, sob o triplo aspecto do conhecimento, do apego e da relação com registros de valores contrastados em termos das escalas 
local/global, pessoal/universal. Estes imaginários diziam respeito aos artistas, aos monumentos, mas também, a título de comparação, às personalidades históricas, aos cientistas e aos atletas;

c) as competências linguísticas: idiomas usuais, línguas de origem dos jovens e de suas famílias próximas;

d) as mobilidades (dos jovens e seus familiares, realizadas ou desejadas) e seus sentimentos de pertencimento e

e) os interesses em relação a certos países.

A estes cinco temas foram acrescentados dados sócio-demográficos a propósito dos jovens, de seus ascendentes e de seus eventuais cônjuges.

2- Por outro lado, foi realizada uma pesquisa, por meio de entrevistas, com 43 jovens de 18 a 29 anos, afim de conhecer suas narrativas a propósito dos temas abordados no questionário e explorar detalhadamente as dinâmicas cognitivas e emocionais relativas aos consumos culturais, em meio ao processo de globalização da cultura. A reflexividade e o caráter aberto, contraditório, reversível, da construção de uma relação cosmopolita com o mundo foram especialmente apreendidos graças a este guia, que incluiu ainda:

a) uma descrição dos repertórios culturais e das modalidades de apropriação - notadamente em relação ao(s) idioma(s);

b) uma investigação dos imaginários do mundo (atração/repulsa em relação a certos países e áreas culturais), de sentimentos de associação e de pertencimento;

c) um questionamento sobre alguns dos grandes temas globais (riscos, solidariedade internacional, ética, meio ambiente, consumo sustentável);

As entrevistas foram realizadas entre 2012 e 2014 com jovens de origens sociais diversas e, principalmente, dos meios urbanos.

\section{0 cosmopolitismo estético-cultural}

\subsection{Dos fluxos internacionais às preferências}

A maioria dos jovens consome numerosos conteúdos, obras e produtos culturais importados, em particular séries, filmes e músicas. A proporção do consumo de con- teúdos estrangeiros é importante para os jogadores de videogames e entre os leitores de livros. Para o consumo dos conteúdos nacionais, os meios como rádio, televisão e impressos, mas também as redes sociais e os websites são, porém, tendencialmente mais importantes (Tabela 1). 
Tabela 1 - Consumos culturais em função da origem dos produtos.

\begin{tabular}{|l|c|c|c|c|c|c|c|c|c|c|c|}
\hline & Séries & Filmes & $\begin{array}{c}\text { Música } \\
\text { gravada }\end{array}$ & $\begin{array}{c}\text { Videoga- } \\
\text { mes }\end{array}$ & Livros & $\begin{array}{c}\text { Quadri- } \\
\text { nhos }\end{array}$ & $\begin{array}{c}\text { Redes } \\
\text { sociais }\end{array}$ & $\begin{array}{c}\text { Websites / } \\
\text { blogs }\end{array}$ & Tevê & $\begin{array}{c}\text { Rádio } \\
\text { (Jornais e } \\
\text { revistas) }\end{array}$ \\
\hline $\begin{array}{l}\text { Exclusivamente } \\
\text { estrangeiro }\end{array}$ & 14 & 3 & 3 & 12 & 2 & 3 & 0 & 1 & 1 & 0 & 0 \\
\hline $\begin{array}{l}\text { Estrangeiro } \\
\text { principalmente }\end{array}$ & 54 & 52 & 37 & 25 & 16 & 7 & 5 & 2 & 1 & 1 & 1 \\
\hline $\begin{array}{l}\text { Nacional e es- } \\
\text { trangeiro em } \\
\text { igual proporção }\end{array}$ & 15 & 30 & 46 & 13 & 25 & 6 & 7 & 8 & 4 & 2 & 4 \\
\hline $\begin{array}{l}\text { Principalmente } \\
\text { nacional }\end{array}$ & 5 & 8 & 11 & 2 & 12 & 4 & 53 & 21 & 9 & 4 & 12 \\
\hline $\begin{array}{l}\text { Exclusivamente } \\
\text { nacional }\end{array}$ & 6 & 6 & 2 & 5 & 9 & 12 & 25 & 58 & 80 & 73 & 66 \\
\hline Não consome & 6 & 1 & 1 & 43 & 36 & 68 & 10 & 10 & 5 & 20 & 17 \\
\hline
\end{tabular}

Amostragem: todos os jovens.

Nota de leitura: 14\% dos jovens, com idade entre 18 e 29, anos só assistem séries estrangeiras, 54\% assistem principalmente séries estrangeiras, $15 \%$ assistem um número proporcional entre séries estrangeiras e francesas, 5\% assistem principalmente séries francesas, apenas $6 \%$ assistem exclusivamente séries nacionais e outros $6 \%$ não assistem séries.

N.B.: Para as redes sociais, trata-se da proporção de contatos/amigos que vivem na França ou no exterior, e para sites e blogs, refere-se à consulta em língua francesa ou em outro idioma.

Esta internacionalização do consumo cultural não constitui por si só um índice de cosmopolitismo $^{2}$, pois este depende das lógicas da oferta: o cosmopolitismo se apreende melhor através das preferências por produtos estrangeiros ou nacionais. A Tabela 2 indica que os jovens apresentam nítida preferência pelos conteúdos culturais estrangeiros, notadamente em matéria de séries, filmes e música. Porém, é preciso enfatizar que, provavelmente, grande parte dos programas televisivos considerados nacionais, pelos jovens, seja, na realidade, formada por licenças de formatos internacionais para adaptações nacionais, cujo sucesso, no horário nobre, remete ao começo dos anos 2000: La nouvelle Star, The Voice, Loft Story, Koh Lanta, Master Chef, FearFactor, etc ${ }^{3}$.

2. Ainda que muitas pesquisas considerem o cosmopolitismo como uma simples abertura ao internacional, nossa perspectiva não se reduz a isto. Ver, por exemplo, Coulangeon (2017).

3. Os programas mencionados são respectivamente: de calouros (La nouvelle star no canal M6, The Voice no TF1, que é uma adaptação de Pop Idol, programa britânico e de The Voice Holland, programa holandês), de competições e aventura (Koh Lanta e Fear Factor no canal TF1, adaptação de The Survivor, programa britânico e Fear Factor, programa americano), de competição culinária (Master Chef no canal M6 é uma adaptação do programa britânico homônimo) ou reality shows (Loft Story no M6, variante do programa holandês Big Brother).

Nota do Tradutor: Na França o canal privado TF1, de sinal aberto, tradicionalmente detém as maiores audiências, seguido pelo canal público France 2. 
Tabela 2 - Preferências por obras e produtos culturais em função de suas origens.

\begin{tabular}{|l|c|c|c|c|}
\hline & Filme & Série & Televisão & Música Gravada \\
\hline $\begin{array}{l}\text { Preferências por obras e pro- } \\
\text { dutos culturais estrangeiros } \\
\text { (Dos quais anglo-saxônicas) }\end{array}$ & 56 & 69 & 6 & 51 \\
\hline $\begin{array}{l}\text { Preferências por obras e pro- } \\
\text { dutos culturais nacionais }\end{array}$ & 8 & 5 & 66 & 19 \\
\hline $\begin{array}{l}\text { Preferências por obras e pro- } \\
\text { dutos culturais regionais }\end{array}$ & 61 & $n p^{*}$ & 1 \\
\hline Sem preferências & 29 & 20 & 21 & 29 \\
\hline Não consome & 1 & 6 & 5 & 1 \\
\hline
\end{tabular}

Amostragem: todos os jovens

Nota de leitura: 56\% dos jovens, de 18 a 29 anos, declaram preferir os filmes estrangeiros aos filmes franceses. Entre estes, a metade prefere filmes anglo-saxões.

*np: "question non posée" - questão não colocada.

\subsection{Dos consumos e dos idiomas}

Se o modo de consumo cultural mais frequente entre os jovens se dá em língua francesa (Tabela 3), como era de se esperar, o inglês tem a primeira posição entre as línguas estrangeiras usadas em consumos culturais: 91\% dos consumos de música em língua estrangeira acontecem pelo menos parcialmente em inglês, 43\% para os filmes, 38\% para as séries, 15\% para a leitura de jornais e revistas, 11\% para a televisão e para a leitura de livros, 4\% para o rádio e leitura de quadrinhos. 0 inglês também é a primeira língua para comunicação e diálogo, entre os jovens pesquisados, em seus lazeres. 30\% o usam para consultas a websites, 24\% para interações nas redes sociais e $21 \%$ para jogar videogames. Mais interessantes ainda são, sem dúvida, os resultados para as outras línguas usadas: 7\%, dentre eles, escutam música e $2 \%$ assistem televisão em árabe; 2\% usam este idioma nas redes sociais; o espanhol é usado por 6\% dos jovens para assistir filmes, o alemão por 3\% e o italiano por $2 \%$. Vemos aí a emergência de novas zonas de produção cultural mundiais não- ocidentais: 5\% dos jovens assistem aos filmes, e 3\% as séries, em japonês. 
Tabela 3 - Idiomas de consumo dos produtos culturais.

\begin{tabular}{|l|c|c|c|c|c|c|}
\hline & Série & Filme & Livro & Videogames & $\begin{array}{c}\text { Música } \\
\text { gravada }\end{array}$ & Quadrinhos \\
\hline $\begin{array}{l}\text { Exclusivamente em } \\
\text { francês }\end{array}$ & 54 & 53 & 52 & 36 & 24 & 27 \\
\hline Maioria em francês & 11 & 19 & 7 & 11 & 31 & 3 \\
\hline $\begin{array}{l}\text { Em francês e em um } \\
\text { ou mais idiomas em } \\
\text { iguais proporções }\end{array}$ & 9 & 10 & 2 & 8 & 26 & 1 \\
\hline $\begin{array}{l}\text { Principalmente em } \\
\text { outro idioma }\end{array}$ & 13 & 13 & 2 & 2 & 14 & 1 \\
\hline $\begin{array}{l}\text { Exclusivamente em } \\
\text { outro idioma }\end{array}$ & 7 & 4 & 1 & 0 & 4 & 0 \\
\hline Não consome & 6 & 1 & 36 & 43 & 1 & 68 \\
\hline
\end{tabular}

Amostragem: todos os jovens.

Nota de leitura: $54 \%$ dos jovens, entre 18 e 29 anos, assistem as séries exclusivamente em francês.

Se a maioria dos consumos culturais dos jovens é realizada em francês, é que quase 41\% declaram dominar ${ }^{4}$ unicamente este idioma (HERAN, 2013). Em nossa pesquisa, a poliglotia dos jovens na França parece relativamente baixa: em média, apenas $30 \%$ dos jovens declararam dominar outra língua além do francês, 23\% duas e 6\% três ou mais. Entre eles, 50\% relataram domínio sobre o inglês, 19\% sobre o espanhol, 6\% sobre o alemão, 4\% sobre o árabe ou italiano, 3\% sobre as línguas africanas, e $2 \%$ sobre o português - o que fica bem abaixo do potencial plurilinguístico da população, se considerarmos tanto as suas origens migratórias, quanto o sistema educacional (que inclui o ensino de duas línguas estrangeiras a partir dos anos iniciais do ensino médio). Assim, parece que muitos hábitos de consumo em língua estrangeira estão desco- nectados de uma competência linguística em seu sentido estrito, além de destacar claramente uma estética da recepção "em versão original" que remete à autenticidade das vozes, dos ambientes sonoros, etc.

\subsection{Os imaginários globais}

0 cosmopolitismo estético-cultural também se apreende através da construção de imaginários culturais e artísticos globais, e de valores aos quais estes imaginários remetem. Esses imaginários globais se apóiam em imagens ou em conteúdos culturais que são fortemente difundidos nas culturas midiáticas. Certos monumentos tornaram-se símbolos nacionais, do Taj Mahal à Estátua da Liberdade, passando pela muralha da China. Os filmes de Steven Spielberg, as canções de Adele, os romance de J. K.

4. Na formulação da pergunta, a idéia de "domínio" era definida como a capacidade de expressar-se oralmente neste idioma. 
Rowling e as pinturas de Salvador Dalí são conhecidos pela maioria dos jovens. Tudo isto contribui para a construção de um re- pertório de referências culturais para grande parte da juventude contemporânea (ver tabelas 4 e 5$)^{5}$.

Tabela 4 - Conhecimento e apreciação dos monumentos.

\begin{tabular}{|c|c|c|c|c|c|c|}
\hline & Os viu & Ouviu falar deles & Desconhece & Gosta & Não Gosta & Não Sabe \\
\hline $\begin{array}{c}\text { Monte } \\
\text { Saint-Michel }\end{array}$ & 47 & 49 & 4 & 87 & 10 & 3 \\
\hline Torre de Pisa & 12 & 78 & 10 & 79 & 18 & 3 \\
\hline $\begin{array}{l}\text { Estátua da } \\
\text { Liberdade }\end{array}$ & 11 & 89 & 0 & 89 & 10 & 1 \\
\hline Pirâmides & 5 & 93 & 2 & 87 & 11 & 2 \\
\hline Ópera de Sydney & 2 & 66 & 32 & 78 & 16 & 6 \\
\hline $\begin{array}{c}\text { Basílica de Santa } \\
\text { Sophia }\end{array}$ & 3 & 33 & 64 & 72 & 17 & 11 \\
\hline Grande Muralha & 2 & 93 & 5 & 79 & 16 & 5 \\
\hline Corcovado & 2 & 74 & 24 & 81 & 15 & 4 \\
\hline Мeca & 1 & 89 & 10 & 50 & 40 & 10 \\
\hline Taj Mahal & 1 & 77 & 22 & 79 & 14 & 7 \\
\hline $\begin{array}{c}\text { Muro das } \\
\text { Lamentações }\end{array}$ & 1 & 69 & 30 & 49 & 37 & 14 \\
\hline Pavilhão Dourado & 1 & 10 & 89 & 63 & 23 & 14 \\
\hline
\end{tabular}

Amostragem: todos os jovens

Nota de leitura : 5\% dos jovens, de 18 a 29 anos, já viram as Pirâmides, 93\% ouviram falar delas sem tê-las visto e $2 \%$ as desconhecem, quer seja pelo nome ou pela experiência. Entre os que as viram ou ouviram falar, $87 \%$ gostam, $11 \%$ não gostam e $2 \%$ não se pronunciaram.

5. Foram submetidas duas listas aos jovens, uma tratando dos monumentos e outra dos artistas. Elas procuraram representar uma diversidade geográfica, histórica e estilística (o objetivo era produzir uma análise global e não por item). A primeira lista incluiu: as Pirâmides de Egito, a Grande Muralha da China, o Taj Mahal, a Estátua da Liberdade, a Torre de Pisa, a Basílica de Santa Sophia, o Corcovado, o Monte Saint-Michel, o Pavilhão de Ouro, o Muro das Lamentações, a Ópera de Sidney e a Meca. A segunda era constituída pelos seguintes artistas: Alexandre Dumas, Hayao Miyazaki, Steven Spielberg, Salvador Dalí, Federico Fellini, Cesária Évora, Adele, J.K. Rowling, Keith Haring, Frédéric Chopin, Gabriel García Márquez e Andy Warhol. Para cada item, perguntamos se eles conheciam "diretamente" (isto é, ter visto os monumentos ou conhecer alguma obra dos artistas), se conheciam de nome ou se não conheciam, se gostavam ou não, deste monumento ou artista. 
Tabela 5 : Conhecimento e apreciação dos artistas.

\begin{tabular}{|l|l|l|l|l|l|l|l|}
\hline & $\begin{array}{l}\text { Já viu/ou- } \\
\text { viu algumas } \\
\text { obras }\end{array}$ & Ouviu falar & Desconhece & & Gosta & Não gosta & Não sabe \\
\hline Steven Spielberg & 82 & 13 & 5 & & 93 & 4 & 3 \\
\hline Adele & 77 & 12 & 11 & & 82 & 15 & 3 \\
\hline Salvador Dalí & 55 & 23 & 22 & & 71 & 18 & 11 \\
\hline Frédéric Chopin & 51 & 25 & 24 & & 65 & 23 & 12 \\
\hline J.K. Rowling & 46 & 10 & 44 & & 84 & 10 & 6 \\
\hline Alexandre Dumas & 45 & 31 & 24 & & 68 & 15 & 17 \\
\hline Andy Warhol & 45 & 23 & 32 & & 69 & 17 & 14 \\
\hline Hayao Miyazaki & 19 & 13 & 68 & & 72 & 9 & 19 \\
\hline Cesária Évora & 16 & 10 & 74 & & 73 & 12 & 15 \\
\hline Federico Fellini & 12 & 17 & 71 & & 54 & 17 & 29 \\
\hline Gabriel García & 11 & 14 & 75 & & 56 & 14 & 30 \\
\hline Márquez & 6 & 9 & 85 & & 63 & 10 & 27 \\
\hline Keith Haring & 6 & & & & & \\
\hline
\end{tabular}

Amostragem: todos os jovens

Nota de leitura : 82\% dos jovens, entre 18 e 29 anos, já assistiram a um filme de Spielberg, 13\% já ouviram falar sem ter assistido e 5\% não conhecem, nem pelo nome, nem por experiência. Entre os que conhecem os filmes de Spielberg ou ouviram falar deles, 93\% gostam deste diretor, $4 \%$ não gostam e $3 \%$ não se pronunciaram.

\subsection{Valores associados aos imaginários globais}

Estes imaginários constituem para os jovens uma bússola que lhes permite orientar-se no mundo. Pedimos aos jovens que defınissem sua relação com os monumentos e artistas em função de quatro dimensões de interesse sem que, para tanto, estas dimensões fossem exclusivas umas em relação às outras. Será que os monumentos e artistas suscitam um sentimento individual de admiração e deleite frente ao belo, ao carisma ou à genialidade? Ou representam um despertar para o mundo e sua percep- ção? São, antes, símbolos da nação que vimos nascer ou parte de uma herança do patrimônio universal? ${ }^{6}$ (Tabela 6).

Para os jovens, os monumentos aparecem diretamente como símbolos nacionais ou universais, e contribuem pouco para a construção de uma visão do mundo; enquanto os artistas remetem, antes de tudo, à sua própria genialidade, antes de acenderem como universais. Com efeito, e acima de tudo, os monumentos são marcadores da cultura e da geografia (se diz: a Grande Muralha da China e as Pirâmides do Egito), antes de serem apreciados por sua beleza.

6. Os jovens interrogados deviam avaliar, numa escala de 0 a 5, em que medida, um monumento ou artista, tinha para eles uma importância, seja por sua beleza ou genialidade, para a construção de uma visão de mundo, para a representação de suas nações, seja por ser parte do patrimônio da humanidade. 
Tabela 6 : Avaliação dos centros de interesse e imaginários cosmopolitas.

\begin{tabular}{|c|c|c|}
\hline & Monumentos & Artistas \\
\hline Beleza / genialidade & 3,9 & 3,6 \\
\hline Visão de mundo & 3,1 & 2,7 \\
\hline Símbolo nacional & 4,2 & 2,8 \\
\hline Valor universal & 4,1 & 3,0 \\
\hline
\end{tabular}

Amostragem: todos os jovens.

Nota de leitura: a pergunta sobre a avaliação dos monumentos por sua beleza obteve nota média de 3,9 sobre 5 .

\section{Cinco configurações do cosmopolitismo estético-cultural}

Se combinarmos os elementos precedentes - internacionalização do consumo cultural, preferências culturais nacionais/ estrangeiras, idiomas de consumo, imaginários globais e valores associados -, podemos distinguir cinco configurações do cosmopolitismo estético-cultural entre os jovens ${ }^{7}$. Esta estratégia deve ser tomada num continuum entre as diferentes configurações, antes de funcionar como tipo-ideal que serviria de padrão para mensurar o cosmopolitismo: em graus, combinações, ordenações diversas e formas "impuras" (BECK, 2011) observadas, movido pelas experiências estéticas e culturais, pelas relações simbólicas com o mundo, seus objetos e representações.

Tais configurações correspondem a três tipos de reações à globalização (Gráficos 1 e 2): a primeira é de imersão sem intencionalidade particular (cosmopolitismo involuntário), a segunda é de engajamento e conhece duas variações (por setor, dar-se principalmente via leitura, e por princípio, isto é, marcada por uma abertura geral), enquanto a terceira é de retração (cosmopolitismo impossível). Estes resultados indicam que o cosmopolitismo é um fenômeno geracional importante para a apreensão das relações culturais num mundo global.

\subsection{0 cosmopolitismo involuntário ${ }^{8}$ : no fluxo da globalização cultural}

Este grupo reúne 34\% dos jovens que têm em comum o fato de apresentar repertórios de consumo abertos - eles assistem tanto séries estrangeiras quanto francesas, ouvem tanto músicas estrangeiras quanto francesas - mas se encontram afastados das práticas nas quais a apropriação linguística é mais complexa, isto é, não consomem nem histórias em quadrinhos, nem livros e jornais ou revistas em língua estrangeira porque não leem em outro idioma. Imersos no mainstream das indústrias culturais, principalmente anglo-saxônicas, declaram

7. Para construir a análise, operamos uma classificação conjunta, aplicada às grandes tabelas de dados mistos (numérica e qualitativa, ao mesmo tempo contínuo, ordinal nominal e binário). A classificação leva em conta 26 eixos de análise em componentes múltiplos, dos quais 50\% em inércia total.

8. Esta qualificação se refere à distinção proposta por Motti Regev entre advertent (voluntário) et inadvertent (involuntário) cosmopolitanism (REGEV, 2007). 
preferir filmes estrangeiros, principalmente americanos, do mesmo modo que preferem séries estrangeiras. Porém, não assistem aos filmes e séries em versão original, privilegiando sempre as versões dubladas. Assim, mais de três quartos destes jovens assistem exclusivamente a filmes em francês. Da mesma maneira, a metade deles joga videogames exclusivamente em francês.

Seus perfis de consumo e seus gostos indicam que os jovens deste grupo figuram entre os que mais assistem ao mainstream televisivo, principalmente programas de entretenimento/auditório ${ }^{9}$, reality-shows, programas de competições/gincanas ${ }^{10}$ e programas musicais; assim como filmes e séries (difundidos em francês nos principais canais abertos e, às vezes, legendados nos canais a cabo). Seus gostos musicais os orientam particularmente para o $R^{\prime} n$ ' $B$ e $R a p$, gêneros internacionais, e para uma audiência cotidiana das emissões de rádio. Os videogames que os caracterizam, são os de esportes.

Esta relativa ausência de investimento voluntário - razão pela qual esta configuração foi chamada de cosmopolitismo involuntário - encontra ressonâncias em seu baixo nível de conhecimento dos monumentos e artistas: um terço destes jovens obtêm resultados muito fracos no conhecimento dos monumentos e dois quintos um resultado fraco. 0 mesmo tipo de distribuição pode ser observada para o seu conhecimento sobre os artistas. Este baixo conhecimento é acompanhado por uma frágil apreciação em proporções similares, para artistas e monu- mentos, mas também por julgamentos de repulsa para mais de um quarto dos jovens. Se eles conhecem pouco, eles são, no entanto, altamente enunciadores de julgamento. Se observarmos as modalidades específicas de seus julgamentos de apreciação, vemos que sua sensibilidade estética é fraca, tanto para os monumentos quanto para os artistas. Além disso, eles estimam ser muito insignificante a contribuição dos monumentos e artistas para as construções de suas visões de mundo. Para eles, os monumentos e os artistas também não são símbolos nacionais, nem elementos ativos na formação de uma visão sobre a humanidade.

Estes jovens, originários dos meios rurais ou habitantes de pequenas e médias cidades, são pouco diplomados. Majoritariamente inclusos no mercado de trabalho, desempenham funções pouco qualificadas e mal remuneradas (operários, assalariados). Eles vivem, mais que a média da população observada, em relação conjugal, assumindo o peso das responsabilidades familiares (parte deles vive em famílias mono -parentais). Em termos de capitais escolar e econômico, provêm de meios sociais desprivilegiados, nos quais as formas tradicionais da família, com a mãe como dona de casa, são as mais recorrentes. 0 que produz efeitos sobre suas representações tanto do trabalho quanto do lazer. Esta reprodução social intergeracional é fortalecida pela escolha de seu companheiro ou companheira, na maioria dos casos pessoas também pouco diplomadas e iniciadas no mundo do trabalho, principalmente nas condições de

9. Nota do tradutor: no original "émissions de divertissement”, seria o equivalente, na televisão brasileira, aos atuais programas de auditório.

10. Nota do tradutor: no original "jeux concours", seria o equivalente, na televisão brasileira, aos programas de auditório, concentrados em jogos, competições e/ou gincanas. 
operários(as) e assalariados(as), e de suas dificuldades (proporção dos que enfrentaram o desemprego é forte).

Particularmente, Margot ${ }^{11}$, ilustra bem esta configuração. Ela ambiciona tornar-se professora do ensino fundamental e ocupa atualmente um cargo de surpervisora num liceu de Paris, classificado como ZEP. Nativa da cidade de Le Mans, ela mora em Paris há dois anos com sua irmã que prepara-se para um concurso de enfermeira. Seus pais trabalham nos serviços dos correios e são titulares do Baccalauréat (diploma nacional sancionando o final do ensino secundário). Margot não se ilude quanto ao seu futuro e acha que ocupará uma posição social comparável a de seus pais. No entanto, ela tem certeza que estará mais preparada culturalmente, para compreender as grandes questões da sociedade. Ela assiste exclusivamente as séries americanas que pertencem, em sua grande maioria, ao repertório mais citado no corpus das entrevistas (à exceção de Mad Men): Grey's Anatomy ${ }^{12}$, How I met your mother, Desperate housewives ${ }^{13}$, em geral pela televisão, mas por vezes em streaming, quando os capítulos não estão disponíveis na tevê. Nestas ocasiões, ela assiste aos capítulos em versão original com legendas, embora este modo de consumo não seja o de sua preferência. Margot privilegia a dublagem.

Suas escolhas cinematográficas misturam filmes estrangeiros e franceses, principalmente aqueles que obtêm as maiores audiências: os três últimos filmes aos quais assistiu foram 0 Ilusionista ${ }^{14}, 2$ days in New York $^{15}$, e um filme com a atriz Juliette Binoche cujo título ela esqueceu. Seu consumo de filmes nacionais e americanos não a impede de incorrer ocasionalmente em outros universos cinematográficos, quando eles têm importante cobertura midiática.

Suas preferências musicais são francesas, mesmo escutando frequentemente músicas em inglês - inclusive quando os cantores são franceses: ela cita como exemplo o grupo folk francês Lilly Wood and the Prick ${ }^{16}$. Ela afirma raramente ouvir músicas em outros idiomas, a menos que estejam ligadas a filmes : "raramente, mais de vez em quando, em espanhol, italiano, isto vem dos filmes estrangeiros aos quais assisto, tipo os filmes do Almodóvar". Raramente, quando não compreende as letras das música em inglês, procura as traduções na internet.

Margot tem uma relação distante com a leitura, quer seja livro ou jornais e re-

11. Mulher, 21 anos, com mestrado em educação, prepara-se para o concurso nacional para professora de escola primária, e trabalha como supervisora num liceu parisiense situado numa área sócio-urbana desprivilegiada (Zona de Educação Prioritária - ZEP). Divide um apartamento com sua irmã, seus pais são franceses. Apesar de diplomada, a moça tem dificuldades econômicas e de inserção social.

12. Série norte-americana exibida desde 2005 (na França, desde 2006 no canal TF1 e desde 2007 em versão multilíngue), encena a rotina de um hospital universitário fictício.

13. Série norte-americana de tipo comédia, exibida entre 2004 e 2012 na França: entre 2006 e 2012 pelo Canal+ (cabo), entre 2006 e 2012 pelo canal M6, e em retransmissão a partir 2013 pelo VM, e desde 2015 pelo Teva. Esta série conta a vida de um grupo de mulheres em Fairview - um bairro periférico fictício -, do ponto de vista de uma delas, falecida recentemente.

14. Filme norte-americano de fantasia, de Neil Burger, lançado em 2007, que trata da rivalidade entre um ilusionista e um príncipe racionalista, ambos apaixonados pela mesma mulher.

15. Filme de tipo comédia romântica franco-germano-belga escrito e dirigido por Julie Delpy, lançado em 2012.

16. Banda pop, folk eletrônica francesa, criada em 2006, e que canta em inglês. 
vistas. Interessa-se, prioritariamente, pelas atualidades internacionais, negligenciando notícias regionais ou nacionais. Ela compensa sua fraca leitura dos impressos em outros canais de informação, em particular a televisão e a internet. "Eu procuro, por exemplo eu vou frequentemente ao site do Le Monde, onde procuro uma informação específica, eu vejo o que pode haver nas notícias internacionais e o que pode me interessar. Muitas vezes, quando eu assisto televisão é para ver o noticiário; mas, se eu quiser me informar minimamente, eu tenho o computador por perto e consulto frequentemente sites do tipo Le Monde para me informar sobre o que pode estar acontecendo no mundo".

\subsection{0 cosmopolitismo setorial: com dispo- sição para a leitura}

Este grupo representa 32\% da população dos jovens pesquisados. É composto por jovens que têm gosto pelas obras, conteúdos e produtos estrangeiros, notadamente em matéria de leitura e consultas a sites e blogs (o que tem a ver com a atividade de leitura). Se eles concedem uma parte importante de suas audiências à televisão, ao rádio e à $w e b$ franceses, nos seus repertórios culturais, estão menos investidos do consumo de filmes e séries que os jovens de outros grupos. Suas preferências estão divididas: assistem séries estrangeiras e programas de televisão nacionais; enquanto suas modalidades de consumo privilegiam o idioma francês. Quando trata-se das dublagens ou da língua original, privilegiam a língua francesa quando assistem aos filmes (duas vezes mais que a média) e as séries (na mesma proporção) mas também quando escutam música (oito pontos a mais). Estes jovens se caracterizam por níveis de leitura mais elevados que a média, e estão particularmente abertos para os idiomas estrangeiros: eles são duas vezes mais numerosos que a média no que se refere às leituras de quadrinhos estrangeiros, e dois terços dentre eles leem, ocasionalmente, livros em idioma estrangeiro e estão quase quatro vezes mais propensos a lerem jornais e revistas em outros idiomas. Desta maneira, seus consumos estão marcados por um cosmopolitismo involuntário vinculado à oferta, e a um cosmopolitismo mais voluntário no caso de certos consumos específicos (em particular as séries), com práticas de leitura fortemente orientadas para produtos internacionais.

Além disso, suas referências são refinadas: figuram entre os melhores conhecedores dos monumentos e artistas e entre os que mais declararam gostar deles. Seu senso estético é apurado: o seu apego declarado aos monumentos e artistas é colocado sob o signo da admiração pelo belo e, este olhar estético, alimenta a importância que conferem aos monumentos e aos artistas na construção de suas visões de mundo, assim como de suas representações do nacional e de suas visões sobre a humanidade. Seu horizonte estético parece aquele de uma nação aberta aos aportes exteriores, abertura que vale tanto do ponto de vista individual quanto coletivo.

Este grupo, onde as mulheres são um pouco mais numerosas, e que reúne aqueles que estão entre os 25 e 29 anos, é um dos mais diplomados e daqueles que comporta mais executivos e intelectuais com altos níveis de formação. Detentores de recursos escolares tanto quanto de recursos econômicos, também estão mais avançados no ciclo de vida (mais de dois a cada cinco neste grupo já têm filhos). Estes jovens encontram-se em situações de reprodução social: seus pais também são diplomados e pertencem a categorias sócio-profissio- 
nais superiores ou intermediárias, e a homogamia conjugal os faz preferir companheiros(as) com perfis próximos, mesmo que ligeiramente socialmente inferiores (assalariados). Eles moram principalmente nas grandes cidades, onde se concentram as universidades, os recursos culturais e as oportunidades profissionais.

0 repertório cultural de Mikael $^{17}$ pode ilustrar esta configuração. Este moço de 21 anos é estudante do segundo ano de uma graduação em japonês, em Paris. Seus pais nasceram no estrangeiro: sua mãe na Argélia (ela é muçulmana) e seu pai no Egito (ele é de religião copta). Moram em Paris, ambos são altos executivos) e tiveram formação universitária em seus países de origem. Mikael é um grande conhecedor das séries televisivas que assiste pela internet. Além das produções mais conhecidas, ele se interessa também pelas $w e b$-séries ${ }^{18}$. Ele também consome muita série televisiva japonesa, as assiste exclusivamente em versão original por razões estéticas - a terceira parte do presente trabalho retornará a este aspecto - e para aperfeiçoar seu conhecimento no idioma original. "[Eu assisto] principalmente as séries japonesas, para treinar meu ouvido e minha dicção".

Mas é seu profundo interesse pela leitura, notadamente por livros e mangás japoneses, que carrega uma firme característica de abertura. Ele lê muito, tanto livros para seu curso de graduação, quanto por lazer ou prazer pessoal. Além disso, pesquisa sobre novas obras, gêneros e autores. "Fora esta grande lista para a universidade [obrigatória para seus estudos de graduação], que é muito interessante, com certeza, acho que é importante ler coisas por si mesmo, de ir procurar, de dizer "Pôxa, o quê que é isto ?", e ter algum orgulho em dizer "este livro fui eu que achei, ninguém me indicou” e, neste caso, fico mais interessado ainda. Eu leio muitas coisas, um pouco sobre mitologias no Japão. Porque não há uma só, é bastante ambíguo, me interessa bastante. Há mundos diferentes, uma dimensão espiritual, há tantas coisas para ver, saber. É bem legal; na realidade, eu gosto desta cultura, adoro esta cultura!"

Para aperfeiçoar as suas competências linguísticas e entender melhor esta cultura que o fascina, ele comprou uma coleção de livros infantis, de contos japoneses: "não deixa de ser uma leitura fácil, de compreensão fácil", diz ele. 0 essencial das obras japonesas que ele lê em versões originais são, no entanto, mangás. "Em versão original, é muito mais fácil acessar. Porque em francês, são poucos os que foram traduzidos, principalmente os mangás para adultos. Na França, editam principalmente aqueles para crianças ou adolescentes. E na internet, posso achar versões onde eles explicam como pronunciar tal ou tal caractere. Então é muito interessante, eu aprendo a leitura dos caracteres e aprendo o seu sentido ao mesmo tempo. Mais uma vez, isto enriquece meu vocabulário, minha fluência, quer seja no cotidiano ou não. Então isto me ajuda a trabalhar em voz alta, a trabalhar minha dicção. Isto ajuda na compreensão das expressões, do vocabulário." Não é de se estranhar, então, que sua paixão pela literatura japonesa o tenha levado a negli-

17. Homem, nascido na França, é também animador em centros de lazeres para jovens. Reside com seus pais em Paris.

18. Séries produzidas para internet e assistidas em canais na $w e b$. 
genciar outros romances, mesmo que muito conhecidos ou que, em geral, foram lidos nesta amostra: $O$ Senhor dos anéis, Harry Potter ou Twilight. Mikael ilustra bem este cosmopolitismo letrado e seletivo.

\subsection{0 cosmopolitismo por princípio: com disposição apriorística}

Terceiro em termos de tamanho (17\% dos jovens), este grupo junta os mais engajados no consumo de produtos estrangeiros, imprime sua marca em todos os campos cobertos pelos seus repertórios culturais. Estes jovens privilegiam as músicas estrangeiras (cerca de sete a cada dez, ou seja, 1,6 vezes mais que a média) e os filmes estrangeiros (quase quatro a cada cinco, ou seja, 1,5 vezes mais que a média). Eles elegem as séries estrangeiras (nove a cada dez, ou seja, 1,3 vezes mais que a média) e os videogames estrangeiros (três a cada cinco, ou 1,6 vezes mais que a média). São mais abertos quanto a assistir aos programas de televisão (um a cada dez assiste principalmente canais estrangeiros, ou seja, quase cinco vezes mais que a média). A abertura do grupo não se limita aos consumos midiáticos, vale também para a leitura e os usos dos recursos multimídia: dois a cada cinco leem, principalmente, histórias em quadrinhos estrangeiras (quatro vezes mais que a média) e livros estrangeiros (duas vezes mais que a média), o que os torna, nesta área, mais cosmopolitas que os do grupo anterior. Mais de um quarto deles fazem consultas online a sites estrangeiros (3,6 vezes mais que a média) e um a cada dez privilegia exclusivamente sites e blogs estrangeiros (três vezes mais que a média). As consultas a sites e blogs também participam desta abertura, pois são duas vezes mais numerosas que a média das consultas.
Este cosmopolitismo pode ser qualificado de "por princípio", pois, além da morfologia de seus repertórios culturais, suas preferências declaradas se orientam, em geral, para o estrangeiro: quer seja em matéria de séries (nove a cada dez), de filmes (os três quintos), de música (três a cada cinco) ou de televisão (um a cada sete, ou seja, duas vezes mais que a média). Suas modalidades de consumo aumentam esta abertura: é neste grupo que achamos a maior proporção de jovens que assistem, leem e escutam música em versões originais. Eles constituem cerca de dois quintos daqueles que, majoritariamente, utilizam a versão original dos produtos, e quase um para cinco as utiliza para assistir filmes (respectivamente 3 vezes e 4,5 vezes mais que a média) e um terço para séries, majoritária ou exclusivamente em versão original (superior, duas ou três vezes, a média). Eles são igualmente mais numerosos na escuta exclusiva (duas vezes mais que a média), e principalmente (1,5 vezes mais), de músicas noutras línguas. De modo semelhante, eles jogam videogames (quatro vezes mais que a média) em língua estrangeira. Atraídos pelas literaturas estrangeiras, leem livros em outros idiomas, na proporção de quatro a cada dez jovens (cerca de quatro vezes mais que a média).

Os perfis de consumo e os gostos destes jovens indicam que são grandes consumidores culturais, que se mantém longe da televisão (quando assistem, escolhem programas culturais e científicos). Parte de seus consumos audiovisuais se faz via internet. Estes jovens são particularmente consumidores de música (gostam de pop rock, techno, dance, metal, jazz, world music e música clássica), de videogames (preferem os jogos arcade, de aventura, RPG, simulação, estratégia, reflexão, esportes e jogos de plataforma) e de leitura (histórias em quadrinhos, livros, demais 
impressos). Eles também consultam websites e blogs (parcialmente, para alimentar suas paixões pela música, pelo cinema, pelos $v i$ deogames, mas também porque se interessam por política e viagens). Além disso, suas leituras de jornais e revistas refletem esta abertura para o mundo: eles leem mais que os outros a imprensa cotidiana e as revistas de notícias gerais, assim como periódicos especializados em cultura, viagens, lazer fora de casa e tecnologia. Suas bibliotecas ideais misturam mangás, quadrinhos franco-belgas, comics, livros clássicos, de ficção científıca, viagens, geografia e ensaios políticos.

Suas referências são ricas, mais ainda que aquelas do grupo precedente, em se tratando de conhecimento ou gosto, mas se distinguem deles por manifestarem julgamentos de rejeição, notadamente no que concerne aos artistas. 0 julgamento de gosto emitido pelos jovens deste grupo aparece como mais seletivo do que o grupo anterior, e menos linearmente dependente do julgamento pelo conhecimento. Estes jovens se distinguem também do grupo anterior, porque os seus vínculos com os monumentos são menos nacionais e com os artistas são mais identificados ao pertencimento a um patrimônio humano. Portanto, seus horizontes são menos aqueles da nação, que da construção de uma visão do mundo como comunidade humana.
Os membros deste grupo, que conta com um pouco a mais de homens, são os mais jovens, os mais diplomados e os mais urbanos. A maioria ainda é estudante, mas aqueles que trabalham já integram mais do que a média das posições profissionais superiores. Seus pais figuram também entre os mais diplomados, os mais numerosos procedentes de categorias sócio-profissionais superiores, e formam casais muito homógamos. Esta homogamia é prorrogada por aqueles jovens que estão casados, em razão de suas escolhas conjugais.

Frédéric $^{19}$ é um exemplo desta configuração. 0 jovem homem de 22 anos vive atualmente em Paris, após passar dois anos em Munique cursando os dois últimos anos do secundário num liceu francês da cidade. Sua mãe é francesa, seu padrasto alemão. Ambos vivem em Paris onde são altos executivos. Frédéric continua seus estudos em ciências políticas numa famosa universidade parisiense. Em sua formação, tem várias estadias e estágios em países anglo-saxões, em particular nos Estados Unidos, Inglaterra, Canadá e Austrália.

As séries fazem parte de seu universo cultural, mesmo que ele tendencialmente desconsidere este aspecto, por considerá -las um gênero cultural menor. Ele declara assistir séries americanas como 24 horas $^{20}$, Ugly Betty ${ }^{21}$, NCIS ${ }^{22}$, How I met your mo-

19. Homem, nascido na França, morou e teve parte de sua formação escolar em Munique, tem pós-graduação em ciências políticas, mora em Paris com sua mãe e seu padrasto.

20. Série norte-americana de ação e espionagem - exibida entre 2001 e 2010 (na França, a partir de 2002 no Canal+ e em retransmissão no canal TF1, a partir de 2003)-, cuja originalidade reside no princípio da unidade de tempo: cada temporada conta 24 episódios representando as 24 horas durante as quais Jack Bauer, o protagonista, tenta frustrar um ataque terrorista.

21. Série de comédia dramática norte-americana exibida de 2006 a 2010 (na França desde 2008 pelo TF1, desde 2010 pelo canal infantil Gulli, desde 2012 pelo NRJ12 e desde 2014 pelo Chérie25). Esta série conta a história de uma mulher à procura de sua beleza interior.

22. Série policial norte-americana exibida a partir de 2003 (e desde 2004, na França, pelo M6). 
ther e, séries alemãs, como Alerte Cobra ${ }^{23}$. Poliglota, ele privilegia as versões em idioma original, inglês e alemão. Amante do cinema, assiste a um filme por dia, escolhendo tanto blockbusters, quanto filmes autorais. Sua voracidade cinematográfica o conduz a pesquisas exaustivas ("eu quase que assisto a tudo que é lançado, faz parte da minha maneira de proceder"), a explorar e enriquecer seu conhecimento sobre as obras de um diretor. "No caso de Thirst ${ }^{24}$, é porque eu já tinha assistido a outros filmes do diretor dos quais eu tinha gostado. Eu vi sua filmografia e é por isto que eu fui ver seu último longa-metragem". Este duplo princípio de conhecimento faz de Frédéric um consumidor ao mesmo tempo eclético e erudito: ao entrevistá-lo encontramos um extenso repertório do patrimônio cinematográfıco mundial. "Sim, eu também assisto aos filmes japoneses. Os dois Kurosawa, isto é, Os Sete Samurais ${ }^{25}$ e A Fortaleza Escondida ${ }^{26}$, e adoro também o Trono Manchado de Sangue ${ }^{27}$. Eu também assisti a alguns filmes do Almodóvar, mas realmente não me atrai. Sim, acho que eu até o detesto. É espanhol. Humm, Fellini, italiano. Cinema alemão, também assisto, mas só conheço o Fritz Lang. Eu vi Solaris ${ }^{28}$, que é russo, mas sou incapaz de nomear o diretor. Tenho certeza que vi outros filmes de outros países, mas sou incapaz de citar todos”. Por outro lado, seu amadorismo o leva a assistir aos filmes sempre em versão original com legendas (independentemente do fato de dominar o idioma).

No caso da música, ele mostra o mesmo ecletismo entre os gêneros. No entanto, ao contrário do cinema, ele exclui as produções nacionais: se escuta tanto música clássica quanto metal, não o faz em relação às canções e bandas francesas. À exceção de Serge Gainsbourg, o único cantor francês por quem tem simpatia. Sua banda preferida é sueca (Apocalyptica ${ }^{29}$ ), e declara gostar de várias bandas alemãs de metal, sobre as quais mostra domínio, em particular, conhecendo categorias e subcategorias do gênero.

0 jovem é um grande consumidor de notícias. Lê muito regularmente a imprensa

23. Série de ação alemã difundida desde 1996 (a partir de 1997, na França, pelo TF1 e após 2006 pelo TMC).

24. Filme do diretor coreano Park Chan-Wook, de 2009, conhecido na França pelo nome First, ceci est mon sang, prêmio do júri no Festival de Cannes de 2009. 0 filme conta a história de um padre morto no decorrer de um experimento médico, que volta à vida graças a uma transfusão de sangue que o transformou num vampiro.

25. Filme japonês dirigido por Akira Kurosawa e lançado em 1954. A ação acontece no Japão medieval, quando uma aldeia recruta sete samurais para se defender de saqueadores. É um dos filmes japoneses mais famosos no mundo (Leão de Prata na Mostra de Veneza em 1954), é considerado, ao mesmo tempo, um clássico entre os filmes de samurais e de ação histórica.

26. Filme japonês dirigido por Akira Kurosawa, lançado em 1958, que conta a aventura épica e cômica de dois camponeses.

27. Filme japonês dirigido por Akira Kurosawa, lançado em 1957, a partir de uma adaptação de MacBeth de William Shakespeare, para um Japão medieval.

28. Filme russo, de Andreï Tarkovski, lançado em 1972 (Grand Prix no Festival de Cannes em 1972), inspirado do romance epônimo escrito pelo polonês Stanislas Lem e publicado em 1961. Ao mesmo tempo, filme de ficção científica e drama psicológico, a narrativa está centralizada na figura de Chris Kelvin, psicólogo enviado a bordo da estação espacial em órbita do estranho planeta Solaris.

29. Banda sueca de metal formada em 1993. 
escrita; em sua universidade os estudantes têm acesso gratuito aos jornais e revistas. Para manter seus hábitos de leitura e interesse pelas notícias do mundo, lê, ainda, o Courrier Internacional e o Le Monde Diplomatique, mesmo declarando ser uma leitura motivada por seus estudos e, portanto, para ele, sem muito prazer. Quando está na Alemanha, ele se informa assistindo aos canais BFM e CNN. Acompanha, igualmente, com menos regularidade, os noticiários alemães, ingleses ou americanos, sem mostrar qualquer tipo de interesse pelas notícias locais.

Por fim, Frédéric declara-se um bom conhecedor dos clássicos da literatura francesa (ele cita Chateaubriand e Balzac) e inglesa (ele lê Shakespeare em inglês, um autor que ele descobriu após assistir ao filme Hamlet ${ }^{30}$ com Mel Gibson). Do mesmo modo, lê romances anglo-saxões traduzidos para o francês (Hemingway, Dan Brown). No caso das histórias em quadrinhos, não gosta de comics, prefere os mangás e, manifesta aqui, um certo domínio sobre as diversas formas de produção asiática. “Bom, o mangá é fácil de adivinhar, é japonês por definição. Senão o nome seria outro. Por exemplo, eu sei que os manhwa são coreanos”. 0 repertório cultural de Frédéric é, então, ao mesmo tempo fortemente investido e eclético, em termos de gêneros e nacionalidade das obras e produtos culturais que gosta, apresentando modos de consumo que privilegiam o uso de línguas estrangeiras.

\subsection{A preferência pela cultura nacional: rejeição à globalização cultural}

A quarta configuração cosmopolita reúne $11 \%$ da população dos jovens entre os
18 e 29 anos. São jovens que se caracterizam por uma firme preferência cultural nacional, quer seja na composição de seus repertórios de consumo, em suas modalidades de consumo, ou ainda em seus imaginários. Mesmo quando expostos ao mainstream internacional das indústrias culturais, operam escolhas muito seletivas, quando observamos a origem dos produtos culturais pelos quais têm afınidades. São cinco vezes menos numerosos que a média ao assistirem aos filmes estrangeiros, e privilegiam, quase sistematicamente, os franceses. 0 mesmo acontece com as séries, são oito vezes mais numerosos que a média ao assistirem, exclusivamente, séries francesas, e quase três vezes mais numerosos que a média ao escutarem só música francesa. São os que menos jogam videogames (a metade contra dois quintos) e, quando jogam, privilegiam jogos franceses (três vezes mais que a média). Leem menos que a média (quatro a cada cinco não leem jornais ou revistas), e também usam menos a web (quase um quarto deles), mas são ativos nos usos das redes sociais, embora privilegiem os contatos franceses. Suas preferências reforçam a centralidade dos produtos nacionais em seus hábitos de consumo: quer sejam filmes, séries, programas de televisão ou escuta de música. Os jovens deste grupo são aqueles que exibem forte predileção por conteúdos franceses (cerca de oito vezes mais para as séries, cinco vezes mais para os filmes e duas vezes mais para a música gravada).

Seus perfis de consumo e gostos indicam que são consumidores culturais moderadamente investidos: seus consumos de filmes são moderados, preferem as séries, a 
maioria nunca joga videogames, não lê (à exceção das eventuais leituras de tablóides e revistas sobre crianças), um quarto deles nunca consulta sites ou blogs pela internet. Concentram-se no hábito de assistir televisão, motivados pelo acesso às séries $\mathrm{e}$ filmes, mas também pelo gosto por reality shows e programas de competições, concursos, gincanas, assim como por programas musicais. Sem surpresa, o idioma usado para estes consumos é o francês: quase exclusivamente para séries, claramente para filmes e programas de televisão, bem como para os videogames. Em se tratando da escuta de músicas, há uma exceção em termos de idioma privilegiado, tendo em vista que o mainstream musical, em inglês, está presente. Estes jovens escolhem, massivamente, as dublagens quando assistem as produções estrangeiras.

As suas referências cosmopolitas são pobres, tanto em relação ao conhecimento dos monumentos, quanto dos artistas: conhecem pouco, gostam pouco e desenvolvem até uma forte rejeição pelos artistas. Assim como no grupo da abertura cosmopolita involuntária, seus níveis de conhecimento e de julgamento não evoluem de maneira paralela: mesmo sendo frágeis conhecedores, exprimem julgamentos de rejeição.

Os jovens deste grupo, composto em sua maioria por mulheres, são muito pouco diplomados. Quando trabalham, são em sua maioria operários ou assalariados. Quase um em cada sete está enfrentando o desemprego. Com menor formação escolar, en- contram maiores dificuldades de inserção no mercado de trabalho. Boa parte deles já tem responsabilidades familiares (quase metade tem filhos e parte deles formaram famílias monoparentais). As condições de vida destes jovens são mais difíceis que as dos grupos precedentes, e sua relação com o lazer é diferente. Eles vêm de famílias pouco diplomadas, que podem apresentar formas tradicionais (mães donas de casa), enraizadas nas culturas operárias, notadamente pelos homens, e de empregados ou de profissões intermediárias pelas mulheres. Aqui também, a reprodução social é acompanhada por uma homogamia: aqueles que estão casados escolheram companheiros(as) também pouco diplomados(as), pertencendo às mesmas categorias sócio -profissionais (operários principalmente). Encontramos estes jovens em todas as áreas urbanas, qualquer que seja seu tamanho.

Nicolas $^{31}$ ilustra esta configuração. Seus pais são de extratos populares: detentores de um certificado de estudos primários; seu pai era agente da companhia elétrica nacional (EDF) e sua mãe é secretária. Nicolas não gosta de leitura, porque ler ocupa muito tempo, num mundo de fluxos no qual tudo tem que ser rápido. Ele lembra ter-se entediado com a leitura do romance de Stephen King Desespero ${ }^{32}$, um romance que integra um gênero - o terror - que ele até gosta, mas no cinema. Da mesma forma, não lê revistas em quadrinhos (nem os autores franco-belgas, nem os comics americanos). Se leu mangás em sua adoles-

31. Homem, 22 anos, com diploma técnico superior (BTS) em contabilidade. Trabalha em alternância modalidade de emprego onde pode dedicar uma parte do tempo aos estudos, mora num alojamento independente na região de Paris e seus pais são franceses.

32. Romance de terror, por Stephen King, publicado em 1996 (Prêmio Locus de melhor romance de terror, em 1997, virou filme e foi adaptado para a televisão). 
cência, foi em virtude de uma atração que rapidamente passou e sobre a qual parece não ter sobrado muita lembrança.

Seu abandono dos mangás correspondeu a uma mudança de gosto e ao maior interesse pelo videogame: "eu prefiro ação, os videogames”. 0 gosto pela ação não o atrai para as séries (mesmo que haja produções deste tipo), ele só assiste aos Misfits ${ }^{33}$, pela internet : "são jovens que se parecem bastante conosco, então é mais interessante do que assistir as séries, as séries antigas, isso tudo não me atrai”. Ele não procura pelos gêneros, ficção, por exemplo, mas pela proximidade e realismo.

Como quase todos os jovens de sua idade, Nicolas ouve muita música, de gêneros variados: rock, hardrock, metal e música eletrônica. No entanto, diz que seu gosto tem mudado e que ele se concentrou numa outra maneira de fazer música, que considera francesa. Antes, Nicolas escutava de tudo ("Quando eu era jovem, eu era mais rock, hardrock, metal, as coisas antigas, de Led Zeppelin a Nirvana”), mas começou a ouvir principalmente bandas francesas como Superbus ou Tryo, antes de concentrar-se na música eletrônica, que considera um gênero musical de origem francesa, que se propagou pelo mundo. "Fora isto, eu agora sou mais música eletrônica, e eletro é muito vasto porque em todos os países, todo mundo está começando com isto, mesmo que tenha havido uma French Touch, que existiu, agora, como todos os países estão fazendo, acho que é uma apelação que não tem mais razão de existir, mas ela existe ainda porque temos grupos muito populares que são realmente franceses, tipo Justice ou Daft Punk”.
Além disto, Nicolas lê poucos jornais e revistas, se interessa pouco pelas atualidades internacionais, preferindo as notícias nacionais. Estar informado lhe serve para conversar ou se posicionar, mais que para elaborar uma reflexão sobre si mesmo.

\subsection{0 cosmopolitismo impossível: a retra- ção cultural}

Este grupo, menor em volume (6\% dos jovens), reúne os jovens que têm consumos culturais claramente inferiores aos homólogos de sua geração e que são também excluídos dos hábitos de consumo que lhes parecem emblemáticos, como a escuta de música gravada ou a visualização de séries. Para eles, a questão do cosmopolitismo se coloca marginalmente, pelas quase ausências de consumo cultural e, portanto, pela inexistência de preferências quanto às suas modalidade de escolhas de conteúdos. Eles não assistem a nenhuma série na televisão, sendo quatro vezes mais numerosos no hábito de não assistir televisão. São, igualmente, numerosos por não jogarem videogame, não lerem livros, histórias em quadrinhos, jornais ou revistas. Não apresentam nenhum perfil para preferências específicas em termos de escolhas de conteúdos e de gostos, associam seu gosto em função das ofertas estrangeiras e nacionais (como a música, por exemplo) e concentram-se nas produções culturais nacionais porque a oferta é abundante ou de fácil de acesso (caso da televisão, por exemplo). 0 único traço cosmopolita que possuem reside no fato de: se por um lado, são mais numerosos na não utilização das redes sociais, quando o fazem privilegiam contatos fora do país. Por outro lado, 
se seus níveis de conhecimento sobre os monumentos e os artistas se situam na média, seus sensos estéticos são frágeis e são raros os que consideram as contribuições dos monumentos para as formações de suas visões de mundo. Além de não declaram afeição, ou alguma outra representação particular, sobre estes objetos.

Este grupo, três quartos dele formado por homens, reúne jovens que tendem a ser diplomados, mas que têm a particularidade de procederem de famílias heterogâmicas (os pais têm níveis de qualificação e modos de inserção no mercado de trabalho diferentes). Por esta razão, estes jovens enfrentam modelos socioculturais e ethos de trabalho híbridos, associados às trajetórias específicas de inserção social: parte deles torna-se operário, mas grande parte torna-se, sobretudo, artesão, comerciante, categorias nas quais a relação entre nível de formação e de renda é, sem dúvida, um dos menos lineares. A escolha do cônjuge reproduz esta heterogamia, pois é neste grupo que os companheiros(as) ocupando altos cargos executivos são em número considerável. Eles residem, principalmente, nas grandes cidades.

Adeline $^{34}$ apresenta traços desta última configuração, mais rara entre a população dos jovens. Esta moça de 18 anos prepara-se para o Baccalauréat (diploma que sanciona o fim dos estudos secundários) de tipo profissional, em secretariado, e reside numa área rural da Normandia. Ela tem uma relação estável com seu companheiro, seis anos mais velho que ela, e irá casar-se brevemente. Os noivos ainda moram com os pais e, após o casamento, irão se instalar no sótão reformado da casa da mãe de Ade- line. 0 pai dela faleceu jovem, e sua mãe, ex-operária, trabalha atualmente em atividades de assistência social. Regularmente, Adeline enfrenta dificuldades financeiras. Ela declara ter sido criada num meio social - "francês de origem" - bastante homogêneo culturalmente, até sua entrada no colégio público, onde deparou-se, pela primeira vez, com adolescentes imigrantes. Esta moça sonha em entrar para a Polícia ou para uma empresa de segurança. "Eu quero enfrentar os que não respeitam. Por que existe uma ordem. Porque, por exemplo, está uma bagunça por tudo quanto é lado, bah, ninguém gosta disto, e para ficar bem para todo mundo é preciso respeitar as coisas".

Ela consome poucos produtos culturais, que são pouco diversificados, ocupando a televisão um lugar central nestes seus hábitos. Adeline declara assistir televisão sem interrupção, de quando volta do Liceu até a hora de dormir. Assiste exclusivamente as séries difundidas pela televisão; sempre em francês, e nunca em versão original ou com legendas. Seus gostos cinematográficos também são muito limitados: só assiste aos filmes de terror, também em francês, quando passam na televisão.

Adeline é também indiferente ao que acontece no mundo: seus referenciais são muito locais. Não se interessa pelas notícias nacionais nem internacionais, assiste aos noticiários regionais, sem manifestar interesse particular pelos conteúdos emitidos: assiste porque, ou está esperando pelo seu programa favorito, ou está sem fazer nada. “Sim, acontece assim mesmo. Quando estou olhando o noticiário, que não tenho mais nada para fazer, eu assisto e escuto, escuto

34. Mulher, nascida na França, com Baccalauréat profissional em secretariado, filha de pais franceses. 
o que tá acontecendo. Todas as noites, antes de Plus Belle la Vie [telenovela francesa], sim, eu assisto ao final do noticiário no canal France 3 [que apresenta as notícias regionais], depois assisto ao programa de esportes e a Plus Belle La Vie”.

Adeline é uma das raras jovens que declara gostar desta telenovela francesa, que lhe permite construir uma imagem exótica sobre Marselha ${ }^{35}$. As vezes lê revistas sobre automóveis, porque gosta de tuning ${ }^{36}$, e nunca lê livros. "Os livros, os romances, este tipo de coisas não. Prefiro ver isto em filmes, eu entendo melhor a história, porque quando eu leio, eu tenho dificuldade em entender. Ou então vou passar um dia lendo um capítulo e um mês depois vou ler o segundo capítulo. Então não, o livro não é comigo". Da mesma maneira, ela prefere os desenhos animados às histórias em quadrinhos. Ela não entende porque alguém lê mangás. "Não, além disso, você tem que lê-los pelo avesso. E enfim, é como os quadrinhos em geral, não é comigo. Eu os vejo em desenho animado e estou bem com isto, e só, estou bem com isto".

Gráfico 1 - Morfologia dos repertórios e das imagens: cinco configurações do cosmopolitismo estético-cultural.

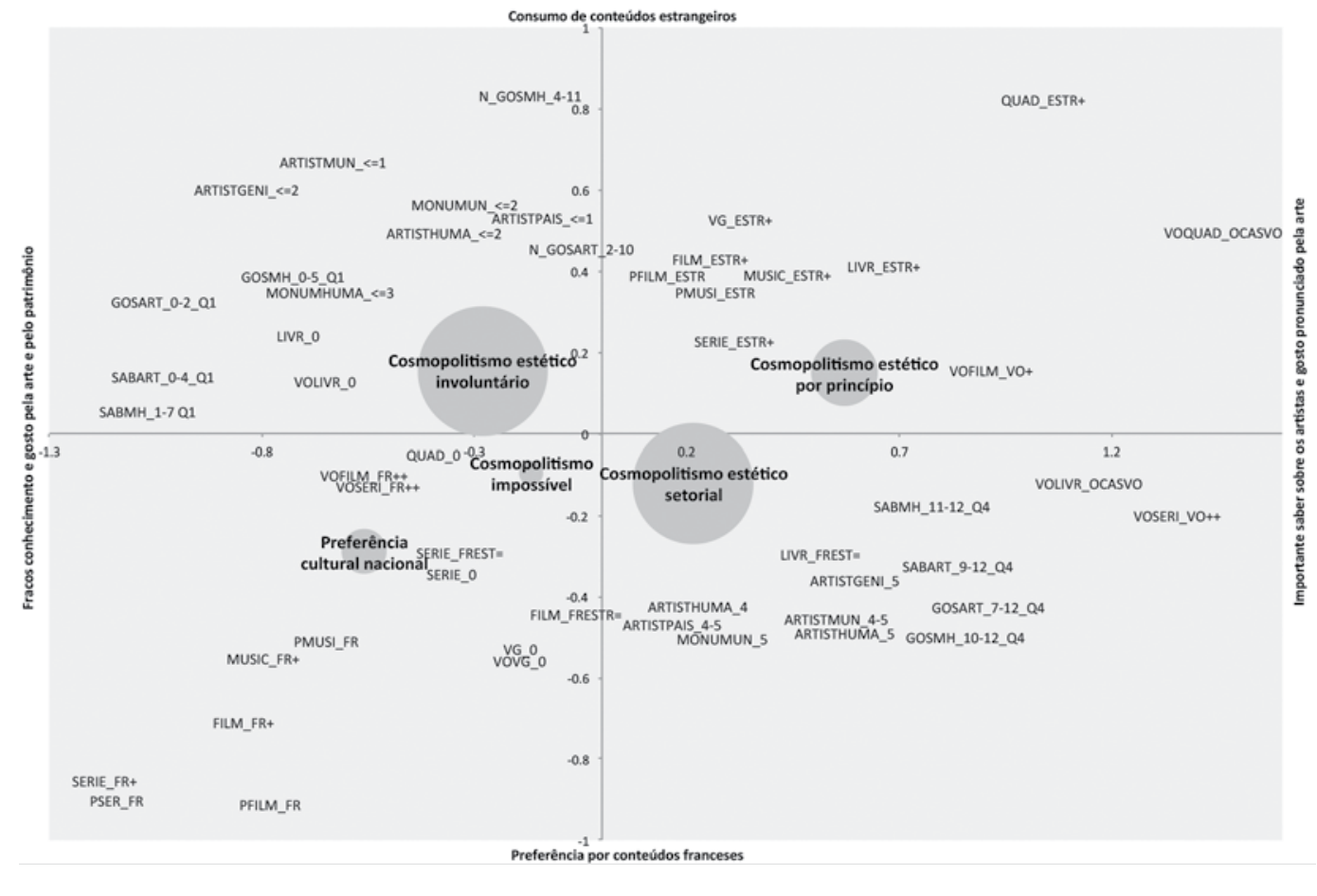

\section{Amostragem : todos os jovens}

Nota de leitura : a análise fatorial foi realizada tomando como variáveis ativas as perguntas que descrevem o cosmopolitismo (morfologia dos repertórios e imaginários) e projetando as classes conservadas nos 26 primeiros eixos que agrupam mais de $50 \%$ do valor explicitado, e calculando o centro da classe (observar grupo $1,2,3,4,5$ ) que apresentamos no gráfico. Os círculos reúnem mais de $80 \%$ dos indivíduos de cada grupo.

35. Nota do tradutor: a telenovela se desenvolve na cidade francesa da costa mediterrânea.

36. Modificação das performances ou da aparência de um automóvel. 
0 eixo horizontal opõe os indivíduos que têm fortes conhecimentos sobre os artistas e que declaram gostar deles (à direita) e os que têm saberes limitados sobre artistas, monumentos e declaram gostar pouco deles (à esquerda). 0 eixo vertical opõe aqueles que apresentam fortes consumos estrangeiros (filmes e videogames estrangeiros em particular) e que tem uma representação dos artistas e dos monumentos centrada na estética mais do que no mundo ou na humanidade (no alto) e aqueles que afirmam uma preferência cultural nacional forte (em particular para filmes e séries) e que retêm os artistas numa representação do país ou do mundo (embaixo).

Para ler este gráfico: o consumo majoritário dos diferentes gêneros (LIVR, FILM, QUAD, MUSI, SERIE, para livro, filme, histórias em quadrinhos, música e série) aparece notado como ESTR+ se for estrangeiro, FRA+ se for francês e FREST= se for na mesma proporção. A preferência por produtos estrangeiros aparece notada como P-ESTR+ se for estrangeira, P-FRA+ se for francesa. 0 uso do idioma de origem aparece notado como $\mathrm{VO}++$ se for exclusivo, $\mathrm{V} 0+$ se for o principal. Os resultados do conhecimento (notados como SAB) e de gostos (notados como GOS ou N_GOS) para os artistas (ART) e os monumentos $(\mathrm{MH})$ são apresentados em quartis do mais fraco ao mais forte (SABART-, SABART+, e SABART++ por exemplo). Enfim, os valores associados aos artistas e aos monumentos foram notados como GENI, MUN, PAIS ou HUMA quando correspondem aos registros estéticos, de visão de mundo, de representação de um país ou de pertencimento à humanidade inteira e, também, são classificados por quartis (de - a ++).

\section{Gráfico 2: Configuração do cosmopolitismo estético-cultural e estratificação social.}

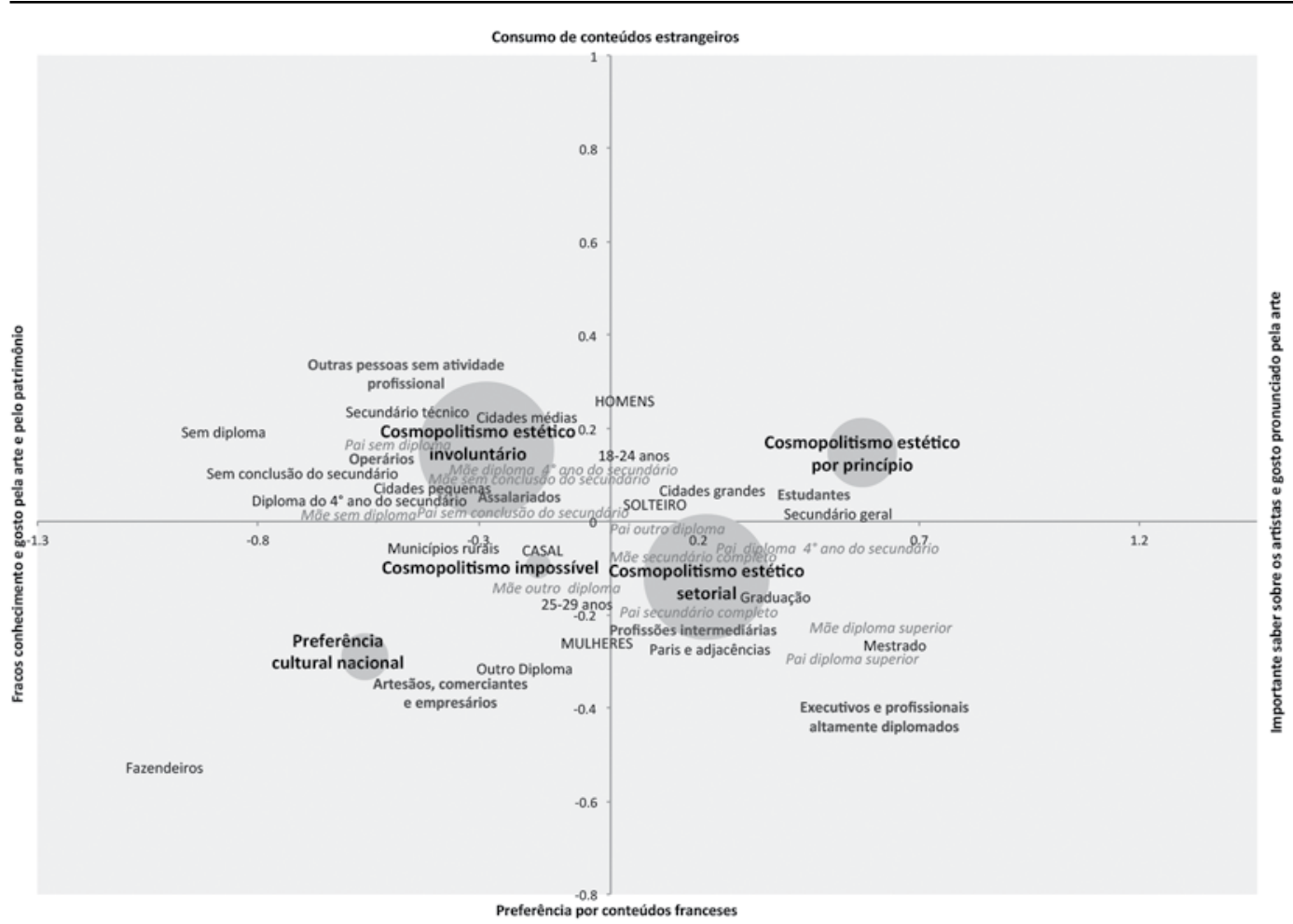

Amostragem: todos os jovens.

Nota de leitura: as configurações do cosmopolitismo estético-cultural figuram em variáveis ativas e as variáveis sócio-demográficas em variáveis passivas. 


\section{Por uma educação para o cosmopolitismo}

0 cosmopolitismo estético-cultural dá conta da maneira pela qual os jovens constroem uma relação com o mundo através do consumo das produções culturais e dos imaginários globalizados. As cinco grandes confıgurações do cosmopolitismo estéticocultural expressam desde um vínculo involuntário com o mundo, pelo consumo, até formas conscientes, intencionais e assumidas de abertura ou de recusa deste mundo. Nunca é demais sublinhar o fato de que a grande maioria dos jovens pesquisados se posiciona frente ao cosmopolitismo estético-cultural, o utiliza como ferramenta para ler e habitar o mundo: as configurações do cosmopolitismo involuntário, setorial ou por princípio perfazem um total de 83\% dos jovens pesquisados.

Os efeitos da globalização das indústrias culturais são muito importantes mas escapam, na maioria das vezes, às instituições de ensino. As novas gerações são cada vez mais cosmopolitas, as produções culturais que lhes atraem têm origens cada vez mais variadas, ainda que existam os polos hegemônicos. Isto nos convida a refletir sobre uma educação cosmopolita. Esta última adquire contornos particulares na medida em que seus principais atores não são estimulados por nenhum programa institucional coerente. De fato, as indústrias culturais e as mídias concorrem entre si e não podemos ver aí nenhuma visão articulada nem o desejo de produzir valores éticos e políticos universais. Isto delineia novos territórios para a educação artística e cultural.
CICCHELLI, V. Pluriel et commun. Sociologie d'un monde cosmopolite. Paris: Presses de Sciences Po, 2016.

CICCHELLI V. e OCTOBRE, S. L'amateur cosmopolite: goûts et imaginaires juvéniles à l'ère de la globalisation de la culture. Paris: MCC, 2017.

CICCHELLI, V.; OCTOBRE, S.; RIEGEL, V. After the Omnivore, the cosmopolitan Amateur. The Global Studies Journal, 9-1, p. 55-70, 2016.

COULANGEON, P. Cultural Openness as an Emerging Form of Cultural Capital in Contemporary France. Cultural Sociology, p 1-20, 2017-1.

DONNAT, 0.; LEVY, F. Approche générationnelle des pratiques culturelles et médiatiques. Culture Prospective, $n^{\circ} 3,2007$.

DONNAT, O. Les pratiques culturelles des Français à l'ère numérique. Paris: La Découverte, 2009.

HERAN, F. L'anglais hors la loi ? Population et sociétés, $n^{\circ} 501$, juin 2013.

IWABUCHI, K. From Western gaze to global gaze: Japanese cultural presence in Asia In: CRANE, D.; KAWASHIMA, N.; KAWASAKI, K. (Dir). Global culture: media, arts, policy and globalization. Routledge: New York, p. 256-273, 2002.

KUIPERS, G. e DE KLOET, J. Banal cosmopolitanism and The Lord of the Rings: the limited role of national differences in global media consumption. Poetics, 37-2, p. 99-118, 2009.

OCTOBRE, S. Deux pouces et des neurones. Les cultures juvéniles de l'ère médiatique à l'ère numérique. Paris: MCC, 2014.

REGEV, M. Cultural Uniqueness and Aesthetic Cosmopolitanism. European Journal of Social Theory 10-1, p. 123-138, 2007.

\section{Referências}

BECK, U. Cosmopolitanism as Imagined Communities of Global Risk. American Behavioral Scientist, v. 55, n. 10, p. 1346-1361, 2011. 
RESUMO

Alguns produtos culturais globais contribuem para a construção de uma representação de um mundo, por vezes, plural - em virtude da diversidade de produtos que circulam internacionalmente - e unificado por certas referências culturais. Oriundas de composições geracionais multiculturais, e sensiveis às injunções de mobilidade (turística, estudantil e/ou profissional), os jovens são atores ativos neste processo de globalização dos produtos culturais. Neste artigo nos interrogaremos sobre os papéis do consumo e dos imaginários culturais na emergência de uma relação cosmopolita com o mundo. Aqui, o conceito de cosmopolitismo estético-cultural é mobilizado para analisar, além dos fenômenos de internacionalização dos repertórios de consumo, as mutações provenientes dos consumos culturais, que têm um impacto na apreensão da alteridade etno-nacional. Assim, distinguimos cinco confıgurações para o cosmopolitismo estético-cultural entre os jovens. Este último, portanto, constitui um continuum antes de ser um tipo-ideal, que serviria de padrão para mensurar o cosmopolitismo: em graus, combinações, ordenações diversas, formas "impuras" observadas, alimentadas tanto pelas experiências estéticas e culturais, quanto pelas relações simbólicas com o mundo, seus objetos e representações.

\section{PALAVRAS-CHAVE}

Globalização da cultura. Cosmopolitismo. Juventude. Consumo cultural e imaginário.

\section{ABSTRACT}

Some global cultural products contribute to the construction of a world representation sometimes plural - in virtue of diversity of the products that circulate internationally and unified by certain cultural references. Coming from multicultural generational compositions and sensible to the mobility injunctions (related to tourism, students and careers), the young are active actors in the cultural products globalization process. In this paper, we question the role of consumption and of the cultural imaginary in the emergence of a cosmopolitan relation with the world. Here the concept of aesthetic-cultural cosmopolitanism is mobilized in order to analyze, beyond the phenomena of the internationalization of the repertoires of consumption, the mutations born from the cultural consumption, which have an impact on the ethno-national alterity. Therefore, we discriminate five different configurations to the aesthetic-cultural cosmopolitanism among the young. The latter constitutes a continuum and not an ideal-type that would serve as pattern to measure cosmopolitanism: in degrees, combinations, diverse ordinations, observed "impure" forms, fed by aesthetical and culture experiences, as well as by the symbolic relations to the world, its objects and representations.

\section{KEYWORDS}

Globalization of culture. Cosmopolitanism. Youth. Cultural consumption and imaginaries. 